\title{
Non-muscle myosin II as a predictive factor in head and neck squamous cell carcinoma
}

\author{
Kelly-Bienk Dias ${ }^{1}$, Anacláudia-Pereira-Costa Flores ${ }^{1}$, Laura-de Campos Hildebrand ${ }^{2}$, Márcia-Gaiger \\ de Oliveira ${ }^{2}$, Marcelo-Lazzaron Lamers ${ }^{3}$, Pantelis-Varvaki Rados ${ }^{4}$, Alessandra-Selinger Magnusson ${ }^{5}$, \\ Manoel-Sant'Ana Filho ${ }^{4}$
}

${ }^{1}$ DDS, Msc., PhD student - Oral Pathology - Universidade Federal do Rio Grande do Sul - School of Dentistry

${ }^{2}$ DDS, PhD. Assistant Professor - Oral Pathology - Universidade Federal do Rio Grande do Sul - School of Dentistry

${ }^{3}$ DDS, PhD. Assistant Professor - Basic Research Center - Universidade Federal do Rio Grande do Sul - School of Dentistry

${ }^{4}$ DDS, PhD. Titular Professor - Oral Pathology - Universidade Federal do Rio Grande do Sul - School of Dentistry

${ }^{5}$ BPharm. Pharmacist - Oral Pathology - Universidade Federal do Rio Grande do Sul - School of Dentistry

Correspondence:

Departmentof Oral Pathology

School of Dentistry

Universidade Federal do Rio Grande do Sul

Av Ramiro Barcelos

2492/503 - 90035-003 - Porto Alegre

Rio Grande do Sul, Brazil

marciago@gmail.com

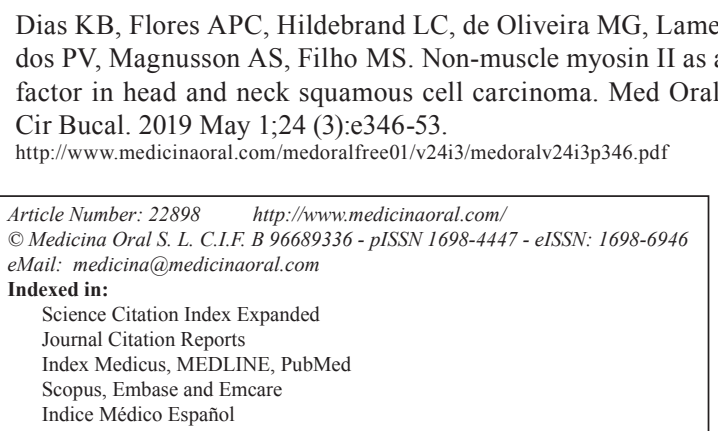

Indice Médico Español

\begin{abstract}
Background: The present study attempted to provide information regarding non-muscle myosin II (MII) isoforms immunoreactivity in patients with head and neck squamous cell carcinoma (HNSCC) and analysis of the patients' clinical status after 5 years of monitoring.

Material and Methods: A semiquantitative analysis of the immunoreactivity of the MII isoforms was performed in 54 surgical specimens and its correlation with clinical and pathological variables and prognosis was verified. Data were analyzed using chi-square, Mann-Whitney and Kruskal-Wallis tests. To evaluate the survival over the total monitoring time and any connection with the proteins studied, the Kaplan-Meier analysis was used. $P$ values $\leq 0.05$ were considered statistically significant.

Results: In the advanced stages of pathological tumor-node-metastasis, the expression of MIIB in adjacent nonneoplastic epithelial tissues tended to increase $(p=0.057)$. In tumoral zones there was an association of high expression among the three isoforms (MIIA/MIIB $p=0,001$, MIIB/MIIC $p=0,006$ and MIIA/MIIC $p=0,012$ ). Negative clinical evolution in patients was directly correlated to increased MIIC expression in the tumoral zone of invasion in HNSCC $(p=0.017)$. Based on clinical evolution after the monitoring period, patients with tumors expressing MIIC had poorer prognoses $(p=0.048)$.
\end{abstract}


Conclusions: The present study suggests that MIIB expression in non-neoplastic adjacent epithelial tissues may indicate a potential for regional metastasis and that MIIC expression in the tumoral zone of invasion is predictive of negative evolution of the disease.

Key words: Head and neck squamous cell carcinoma, oral cancer, myosin type II, non-muscle myosin, immunohistochemistry.

\section{Introduction}

Squamous cell carcinoma, a disease linked to risk factors such as tobacco and alcohol consumption, is the most common malignant neoplasm of the head and neck (HNSCC). In addition to these major risk factors, sun exposure, eating habits and types 16 and 18 of human papillomavirus (HPV) are related to the pathogenesis of the disease, mostly in the oropharynx (1). Despite advancements in treatment, the mortality rate of HNSCC continues to be high and the survival rate low (2). Tools for provision of prognostic information for patients suffering from malignant neoplasia, such as histological grading and the TNM system, are questioned by some studies since a solid tumor such as HNSCC presents an uneven cellular population, resulting in different behaviors in distinct tumor zones, often masking the real degree of progression of the disease (3). The causes of treatment failure and poor prognosis include tissue invasion and development of metastatic potential, which is regulated by molecular alterations such as modifications to cellular adhesion to the extracellular environment, allowing displacement of the cell, an indispensable process for tumor progression $(4,5)$. Among the molecules involved in cellular locomotion, type II non-muscle myosin (MII) plays a key role in regulation of different migratory events through generation of contractile forces that align actin filaments and control adhesion maturation, nucleus displacement, and cellular body retraction during cytokinesis $(3,5)$. The present study attempted to provide information concerning the immunohistochemical expression of MII isoforms (A, B, and C) in patients with HNSCC through evaluation of MII immunoreactivity in surgical specimens, and analysis of patient clinical status after 5 years of monitoring.

\section{Material and Methods}

\section{-Description of the Sample}

This sample is composed by 54 patients included in a previous study approved by the Research Ethics Committee of the Porto Alegre Clinical Hospital (HCPA) on August 28, 2009 (09-315). The collection lasted twelve months from October 2009 and was composed by patients diagnosed with HNSCC and treated at the Surgery Ambulatory of Head and Neck in the HCPA. All individuals were older than 18 years at the time of diagnosis, and they each signed an informed consent form as well as answered a survey used to obtain demographic data such as age, gender and deleterious habits including tobacco and alcohol. Paraffin blocks were prepared with the HNSCC samples and the tumor clinical data was performed at the time of surgery (6). After this, these patients were followed up until July 2015.

-Evaluation of Tumor Samples

Histological cuts of $3 \mu \mathrm{m}$ were obtained from the paraffin blocks prepared earlier (6) and stained with hematoxylin and eosin. For each HNSCC sample, tumoral zones were identified as the center of the tumor (CT) and the zone of invasion (ZI), as well as non-neoplastic adjacent epithelial tissues (AE) (7) (Fig. 1).

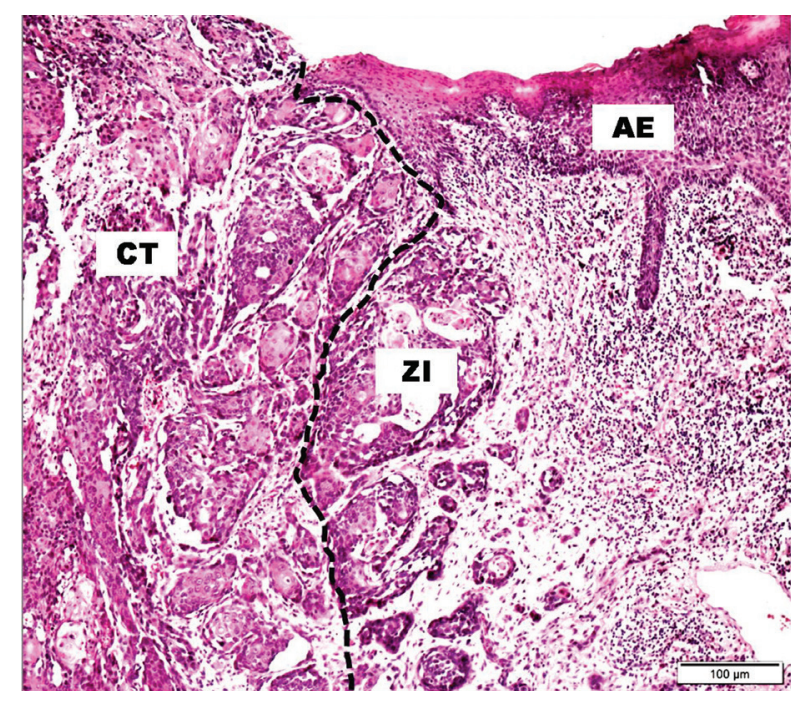

Fig. 1. Representative hematoxylin and eosin staining of the HNSCC center of the tumor (CT), zone of invasion (ZI), and adjacent non-neoplastic epithelial tissues (AE). Original magnification 200×. SOURCE: Oral Pathology FO/UFRGS.

Histological grading was performed according to the criteria of Bryne et al. (8) by two pathologists (A.P.C.F and K.B.D), in which a score was attributed for each morphological characteristic being evaluated, and individual scores were combined to determine to which group of malignancy the specimen belonged: low, moderate, or high.

-Clinical Staging

Clinical data of the tumors, such as tumor size $(\mathrm{T})$, node status $(\mathrm{N})$, and the presence of metastases (M),were tabulated and classified according to the TNM system, 
following the parameters established by The American Joint Committee on Cancer, during the examination of the surgical specimens (pTNM) (9). The outcome of 5 years of follow-up was classified as failure (local recurrence, regional or distant metastasis and death due to tumor) or disease-free survival (7).

-Immunohistochemistry

Histological sections of $3 \mu \mathrm{m}$ were made using silanized slides for immunostaining of the MII isoforms (A, B, and C). Initially, the cuts were deparaffinized in xylol, rehydrated in a gradient of alcohol and water, and immersed in 3\% hydrogen peroxide solution to block the endogenous peroxidase activity. Afterwards, they were submitted to antigen retrieval and incubated with primary antibodies anti-MIIA, anti-MIIB, and anti-MIIC (IIA, polyclonal; IIB, clone D8H8; IIC, clone D4A7; rabbit antibodies; Cell Signaling; 1:50 dilution). Antigen retrieval of the anti-MIIA epitope was conducted by incubation in a pressure cooker at $120^{\circ} \mathrm{C}$ for $3 \mathrm{~min}-$ utes and of the anti-MII B and C epitopes by treatment with $0.25 \%$ trypsin for 30 minutes. Incubation of all antibodies was conducted at $4{ }^{\circ} \mathrm{C}$ overnight. A positive control (stomach adenocarcinoma) and a negative control (non-immune serum from the same animal species as the primary antibody) were used according to the manufacturer's instructions. The detection system used was polymeric (Envision dual link; Dako, Carpentaria, CA, USA), and the samples were developed with a chromogen solution containing $0.03 \%$ 3-3,3'-diaminobenzidine (DAB, DakoCytomation, USA). The samples were counterstained with a solution of Mayer's hematoxylin.

-Data Analysis

Tumoral cells that presented brown cytoplasmic stainingwere considered positive for MIIA, MIIB, and MIIC. The immunostained histological cuts were submitted for semi-quantitative analysis based on the extent of immunoreactivity. Samples were considered positive when more than $30 \%$ of the tumor cells were marked. Immunohistochemical analysis was performed by two pathologists (A.P.C.F and K.B.D), and reproducibility was confirmed over the study period by randomly selecting one out of every 10 slides for reassessment after a 7-day interval (kappa $>0.7$ ). During the evaluation, examiners were blinded to the origin of the material.

-Statistical Analysis

Data were analyzed using SPSS version 21. The relationship between the immunostaining of the proteins was evaluated using the chi-squared test; the immunostaining distribution of the proteins in the tumoral zones according to the evolution, and exposure to alcohol and smoke were verified by Mann-Whitney tests. KruskalWallis tests were used to evaluate the distribution of the protein immunostaining in the tumoral zones, according to the histological grading and pTNM system. To evaluate survival over the total time of monitoring and any connection to the studied proteins, Kaplan-Meier analysis was used. $P$ values $\leq 0.05$ were considered statistically significant.

\section{Results}

Among the patients evaluated, $85.2 \%$ were men and $14.8 \%$ women, the mean age was 58.3 , and the predominant age group was over 65 years old. The majority of the occurrences of HNSCC were in the mouth $(68.5 \%)$ in relation to the patients affected in the neck (31.5\%) (Table 1).

According to the pTNM system, $63 \%$ presented tumor sizes between $\mathrm{T} 1$ and $\mathrm{T} 2,64.8 \%$ did not present regional metastasis (N0), and there were no distant metastases (MX, M0, and M1) (Table 1). In advanced pTNM stages, the expression of MIIB in AE tended to increase $(p=0.057)$ (Table 1).

According to histological grading, $48.1 \%$ of the HNSCC samples were of moderate grade, and no statistical correlations between the expression of MIIs in the AE and the tumoral zones were observed (Table 1).

At the time of the diagnosis, $38.9 \%$ of the patients were exposed to tobacco and $48.1 \%$ to alcohol (Table 1). Of the patients exposed to alcohol, $83.3 \%$ had maintained their habit for a period longer than 10 years. At an average of 4.7 and 6.3 years before HNSCC diagnosis, $55.5 \%$ of the patients had ceased tobacco use and $46.3 \%$ had stopped alcohol consumption, respectively.

There was no statistically significant correlation between exposure to tobacco and alcohol with protein expression. However, in patients exposed to alcohol, a correlation with immunostaining for MIIA $(p=0.048)$ and MIIB $(p=0.010)$ was found in the AE (Table 2).

In tumoral zones, there was an association of high expression among the three isoforms (Table 2).

The maximum time of monitoring was 5.9 years, and from the total of 54 initial patients, we obtained the final status for 46 patients. Among these patients, 58.1\% showed positive evolution (disease free survival) and $41.9 \%$ exhibited negative evolution (treatment failure). The average number of years for patients to present failure was 5.01.Negative clinical evolution in patients was directly correlated to increased MIIC expression ( $p$ $=0.017)($ Table 3$)$ in the ZI of the HNSCC cases (Fig. 2). Based on the evolution after the monitoring period, patients with tumors with MIIC expression had poorer prognosis $(p=0.048)$ (Fig. 3).

\section{Discussion}

The mean age of the patients assessed in this study was 58.3 years, while $29.6 \%$ of patients were over 65 years old, in agreement with the literature (10). In the patient sample described, $85.2 \%$ were men, which correlates well with a 2- to 4-fold higher incidence of male suffer- 
Table 1. Demographic data and tumor features.

\begin{tabular}{|c|c|c|c|}
\hline \multicolumn{2}{|l|}{ Clinical Parameters } & \multirow[t]{2}{*}{$\mathbf{n}$} & \multirow[t]{2}{*}{$\%$} \\
\hline Age & & & \\
\hline Mean & 58,3 & - & - \\
\hline \multirow[t]{5}{*}{ Range } & $\leq 50$ & 15 & 27,8 \\
\hline & $51-55$ & 05 & 11,1 \\
\hline & $56-60$ & 10 & 18,5 \\
\hline & $61-65$ & 07 & 13,0 \\
\hline & $\geq 65$ & 16 & 29,6 \\
\hline \multirow[t]{2}{*}{ Gender } & Male & 48 & 85,2 \\
\hline & Female & 08 & 14,8 \\
\hline \multirow[t]{3}{*}{ Tobacco } & Current & 21 & 38,9 \\
\hline & Former & 30 & 55,5 \\
\hline & Never & 03 & 5,60 \\
\hline \multirow[t]{3}{*}{ Alcohol } & Current & 26 & 48,1 \\
\hline & Former & 25 & 46,3 \\
\hline & Never & 03 & 5,60 \\
\hline \multirow[t]{3}{*}{ Histological Grading } & Low & 25 & 46,3 \\
\hline & Moderate & 26 & 48,1 \\
\hline & High & 03 & 5,60 \\
\hline \multirow[t]{2}{*}{ Size } & $\mathrm{T} 1 / \mathrm{T} 2$ & 34 & 63,0 \\
\hline & $\mathrm{T} 3 / \mathrm{T} 4$ & 20 & 37,0 \\
\hline \multirow[t]{2}{*}{ Regional metastases } & N0 & 35 & 64,8 \\
\hline & N1/N2/N3 & 19 & 35,2 \\
\hline \multirow[t]{2}{*}{ Localization } & Mouth & 37 & 68,5 \\
\hline & Neck & 17 & 31,5 \\
\hline Total & & 54 & 100 \\
\hline
\end{tabular}

ing from HNSCC in comparison to female, according to data described by Globocan (11).

The TNM system, although suggested as a useful tool for forming therapeutic decisions, is not indicated for prognostic prediction. This makes it necessary to obtain more prognostic tools, such as markers related to the metastatic process (12). This was confirmed in this study, where the majority of patients were in the early stages $(\mathrm{T} 1 / \mathrm{T} 2=63 \%, \mathrm{~N} 0=64.8 \%)$ and the evolution rate was highly negative $(41.9 \%)$. We have to consider that one of the limitations of this study is that at the time of sample collection (2009) the condition of the patients in relation to HPV was not investigated since the HNSCC related to this viral infection predominate in the region of oropharynx and present different clinical, microscopic and molecular features (13). Only in the year 2017 was the new TNM edition published, considering a different staging for HPV positive patients, confirming this condition as a limitation not only of this study but for the staging of the disease itself (14).

Corroborating studies that questioned the value of histological grading as a predictive factor for prognosis
(12), only 5.6\% of HNSCC samples from this study had high histological grades, and the proportion of patients with good evolution (58.1\%) was small.

Analysis of the behavioral profile of tumoral zones is indispensable since a cell population in the ZI of the HNSCC resembles that found in metastases (8). In addition, adhesion molecules can present a similar behavior involving tumoral zones and AE (15), indicating that molecular evaluation of AE may provide information concerning tumor behavior (6). Our results suggest that the more advanced pTNM stages correspond to higher MIIB immunoreactivity in AE $(p=0.057)$. Considering that tumors such as melanoma, with high potential for tissue invasion and metastasis, express high levels of MIIB (16), it is possible to suggest detection of MIIB expression in $\mathrm{AE}$ as a potential sign of regional metastasis. Myosin IIB may contribute to cancer cell invasion by maintaining cell contractility, which is required for their passage through pores in the extracellular matrix $(13,17)$.

Traditionally, in $80-90 \%$ of patients suffering from HNSCC, the disease is related to alcohol and tobacco 
Table 2. Isoforms expression frequency and their associations.

\begin{tabular}{|c|c|c|c|c|c|c|c|}
\hline \multicolumn{8}{|c|}{ Frequency of protein expression } \\
\hline & \multicolumn{4}{|c|}{ Adjacent epithelium } & \multicolumn{3}{|c|}{ Tumoral zones } \\
\hline & MIIA & \multicolumn{2}{|r|}{ MIIB } & MIIC & MIIA & MIIB & MIIC \\
\hline $\mathrm{n}$ & 38 & \multicolumn{2}{|r|}{35} & 41 & 44 & 42 & 38 \\
\hline$\%$ & 70,4 & \multicolumn{2}{|r|}{64,8} & 75,9 & 81,5 & 77,8 & 70,4 \\
\hline \multicolumn{8}{|c|}{ Distribution and association of protein immunostaining } \\
\hline & & n & $\%$ & TNM & $\begin{array}{c}\text { Histological } \\
\text { Graduation * }\end{array}$ & $\begin{array}{l}\text { Exposed to } \\
\text { tobacco * }\end{array}$ & $\begin{array}{l}\text { Exposed to } \\
\text { alcohol * }\end{array}$ \\
\hline \multirow[t]{3}{*}{ MIIA } & $\mathrm{AE}$ & 45 & 83,3 & 0,347 & 0,253 & 0,472 & 0,048 \\
\hline & $\mathrm{CT}$ & 43 & 79,6 & 0,696 & 0,346 & 0,279 & 0,143 \\
\hline & ZI & 49 & 90,7 & 0,976 & 0,141 & 0,823 & 0,197 \\
\hline \multirow[t]{3}{*}{ MIIB } & $\mathrm{AE}$ & 44 & 81,5 & 0,057 & 0,359 & 0,792 & 0,010 \\
\hline & $\mathrm{CT}$ & 37 & 68,6 & 0,268 & 0,220 & 0,919 & 0,165 \\
\hline & ZI & 43 & 79,6 & 0,210 & 0,139 & 0,919 & 0,165 \\
\hline \multirow[t]{3}{*}{ MIIC } & $\mathrm{AE}$ & 44 & 81,5 & 0.426 & & 0,759 & 0,546 \\
\hline & $\mathrm{CT}$ & 38 & 70,4 & 0,926 & & 0,871 & 0,286 \\
\hline & ZI & 44 & 81,5 & 0,324 & & 0,596 & 0,547 \\
\hline \multicolumn{8}{|c|}{ Association of the protein immunostaining in the Tumoral Zones } \\
\hline \multicolumn{2}{|c|}{ MIIA/MIIB } & & \multicolumn{2}{|c|}{ MIIB/MIIC } & \multicolumn{3}{|c|}{ MIIA/MIIC } \\
\hline \multicolumn{2}{|c|}{0,001} & & \multicolumn{2}{|c|}{0,006} & \multicolumn{3}{|c|}{0,012} \\
\hline
\end{tabular}

* $p$ values $\leq 0.05$ were considered significant. TNM, histological graduation: Kruskal-Wallis test; Exposed to tobacco, exposed to alcohol: Mann-Whitney test; Association of protein immunostaining in tumoral zones: chi-square test.

Table 3. Clinical evolution and its relationship with protein immunostaining.

\begin{tabular}{|c|c|c|c|c|c|c|c|c|}
\hline \multicolumn{2}{|c|}{ Patients' evolution } & \multicolumn{2}{|c|}{ Positive evolution } & \multicolumn{2}{|c|}{ Negative evolution } & \multicolumn{2}{|c|}{ Total } & $\begin{array}{l}\text { Mean of years for } \\
\text { diagnostic failure }\end{array}$ \\
\hline \multicolumn{2}{|c|}{$\begin{array}{l}\mathbf{n} \\
\%\end{array}$} & \multicolumn{2}{|c|}{$\begin{array}{c}24 \\
58,1\end{array}$} & \multicolumn{2}{|c|}{$\begin{array}{c}22 \\
41,9\end{array}$} & \multicolumn{2}{|c|}{$\begin{array}{c}46 \\
100\end{array}$} & 5,01 \\
\hline Isoform & $\begin{array}{c}\text { Tumoral } \\
\text { Zones }\end{array}$ & $\mathbf{n}$ & $\%$ & $\mathbf{n}$ & $\%$ & $\mathbf{n}$ & $\%$ & $p$-value * \\
\hline \multirow{3}{*}{ MIIA } & $\mathbf{A E}$ & 21 & 38,9 & 13 & 24 & 34 & 62,8 & 0,625 \\
\hline & CT & 21 & 38,9 & 12 & 22,2 & 33 & 61,1 & 0,954 \\
\hline & $\mathbf{Z I}$ & 24 & 44,4 & 15 & 27,5 & 39 & 72,2 & 0,179 \\
\hline \multirow{3}{*}{ MIIB } & $\mathbf{A E}$ & 20 & 37,0 & 13 & 24,0 & 33 & 61,0 & 0,806 \\
\hline & CT & 17 & 31,5 & 09 & 16,7 & 26 & 48,2 & 0,574 \\
\hline & $\mathbf{Z I}$ & 20 & 37,0 & 12 & 22,2 & 32 & 52,2 & 0,507 \\
\hline \multirow{3}{*}{ MIIC } & $\mathbf{A E}$ & 20 & 37,0 & 13 & 24,0 & 33 & 61,0 & 0,952 \\
\hline & CT & 18 & 33,3 & 09 & 16,6 & 27 & 49,9 & 0,247 \\
\hline & ZI & 20 & 37,0 & 13 & 24,0 & 33 & 61,0 & 0,017 \\
\hline
\end{tabular}

The " $\mathrm{n}$ " and percentages correspond to simultaneous immunostaining and to the final status of the patients; *Mann-Whitney test. 

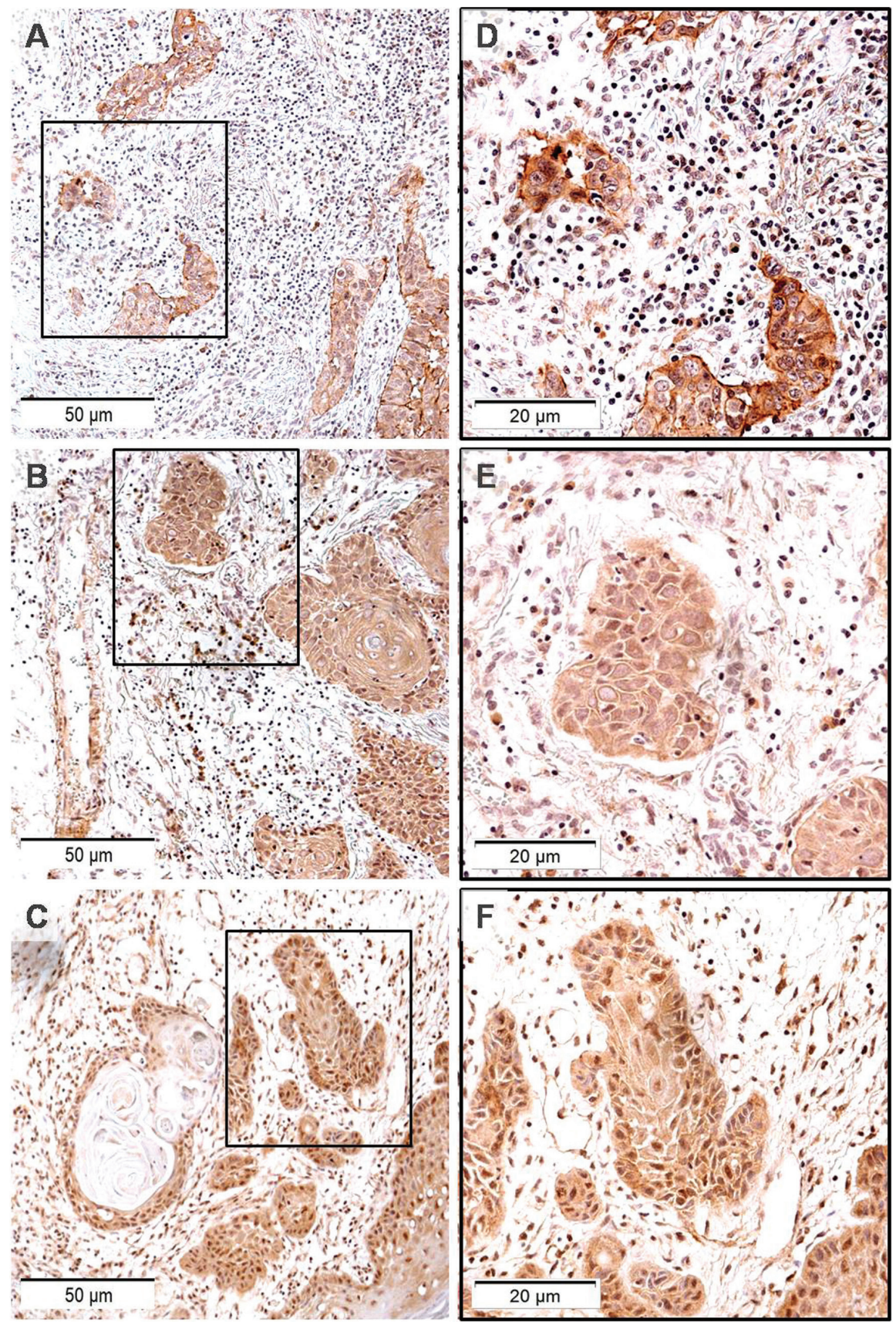

Fig. 2. Representative images of MIIC immunolabeling in ZI of HNSCCs: A, B and C original magnification 200×; D, E and F, highlighting cytoplasmic and nuclear marking. Original magnification 400×. SOURCE: Oral Pathology FO/UFRGS.

exposure (18). A possible challenge to this assumption can be made based on the present sample since there were a number of patients who stopped their habits long before development of the disease. This decrease in the number of patients exposed to risk factors for HNSCC may be attributed to new initiatives in public health targeting the prevention of HNSCC and related illnesses (19). Nevertheless, we have to consider that an important number of our sample $(31.5 \%)$ is of the neck region, and that, $70.4 \%$ of the sample was composed by younger patients (below 65 years). Since HPV is related to the pathogenesis of the disease mostly in the oropharynx in younger patients (1), our data suggest, that HNSCC development may have HPV as an etiological factor. Further studies are needed to define the role of HPV in HNSCC carcinogenesis; however, it is possible that interactions between HPV oncoproteins and cell cycle mediators lead to cell cycle progression, 


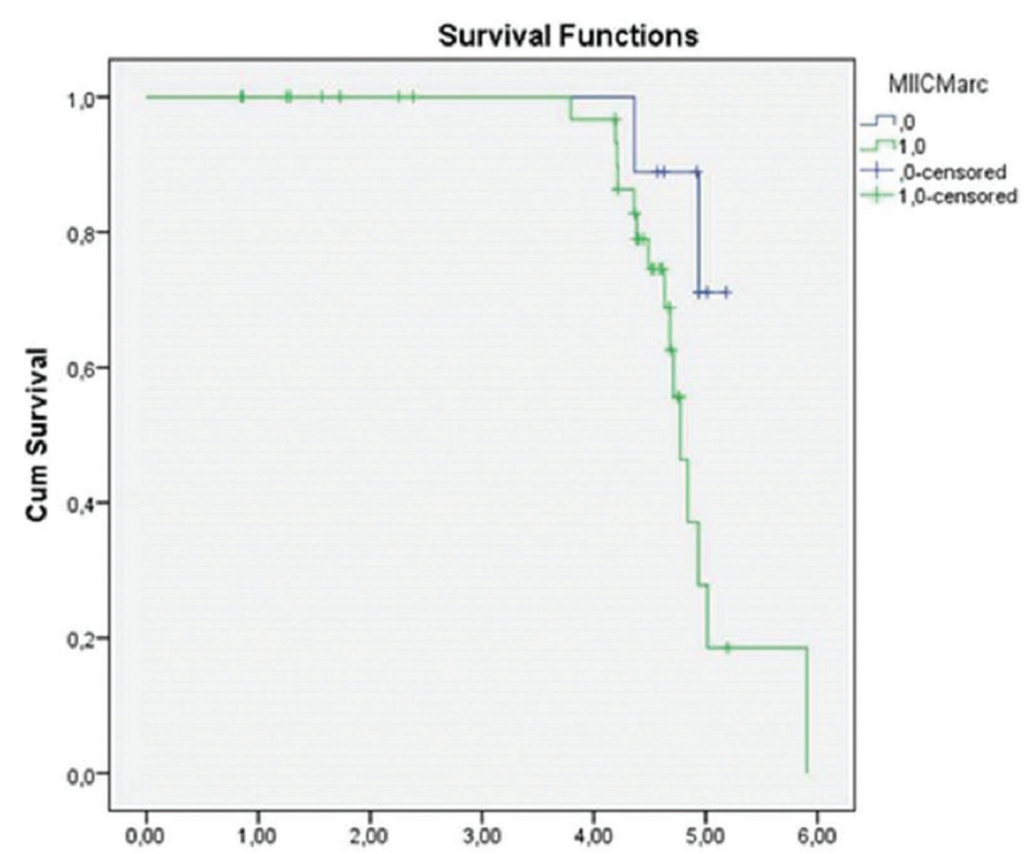

Fig. 3. Kaplan-Meier curve showing, according to the time of monitoring, the evolution of survival in patients with tumors showing MIIC expression (0.146, standard deviation, $95 \%$ confidence.

cell immortalization, apoptosis suppression and essentially decoupling of proliferation and maturation, causing the HNSCC (1).

A correlation was observed between immunostaining for MIIA $(p=0.048)$ and MIIB $(p=0.010)$ in AE in patients exposed to alcohol for periods longer than 10 years. According to studies of the relationship between alcohol consumption and HNSCC, it was observed that chronic alcohol consumption can cause a reduction in epithelial thickness and consequently an increase in cellular desquamation, causing an adaptive response of the epithelium and increasing the proliferation of the basal coat (20) and the possibility of errors during DNA duplication. Additionally, proto-oncogenes as well as tumor suppressor genes, which are altered during alcohol exposure, may influence the expression and/or regulation of MII isoform activity $(21,22)$. Considering that the damage caused by alcohol is related to the duration of exposure $(20,23)$, since the cell has DNA damage and acquires tumoral behavior, it can assume a migratory phenotype by activation of MIIA and MIIB (24).

During cellular migration, there is cooperation between MIIA and MIIB because during the protrusion of the cellular body, MIIA is responsible for adhesion between cells and the extracellular environment, whereas MIIB is responsible for stabilization of adhesion complexes. This synergy may justify the fact that in the tumoral zones, increased MIIA expression is related to increased MIIB expression ( $p=0.001)(25)$.

The present study demonstrated the presence of MIIA in both $\mathrm{AE}$ and tumoral zones. However, it does not correlate this presence with either clinical staging or clinical outcome. Even so, it is important to note that the literature contains paradoxical findings regarding this protein (17). In pulmonary adenocarcinoma, it was observed that patients who did not present immunoreactivity to MIIA had no cancer recurrence for 5 years, concluding that non-expression of MIIA is a predictive factor for good evolution, in agreement with other studies involving esophageal and stomach carcinomas $(26,27)$. These studies appear to contradict the reports by Schramek et al. (28) and Conti et al. (29) that state that loss of MIIA appeared to be related to tumor initiation.

MIIC is one of the proteins responsible for breaking intercellular bridges present during final cell division. Defects in this process may result in binucleated cells and alterations in the expression and/or activity of this protein, generating abnormal cytokinesis, which could foster the propagation of genetic defects such as aneuploidy $(30,31)$ in breast and pulmonary cancer cell lines. Takaoka et al. suggested that formation of the contractile ring at the last step of cell division depends on MIIC as a critical stage in cytokinesis, offering an explanation for how chromosomal instability may arise in breast cancer (32). This study showed that there was a worsening of the prognosis of patients whose tumors expressed MIIC ( $p=0.048)$ (Fig. 2) and that negative evolution in patients was correlated to increased MIIC in the ZI ( $p$ $=0.017$ ). Since tumoral progression occurs in the ZI, and because the physical forces generated by MIIC are necessary for cell division, we can suggest that MIIC 
expression in the ZI is a predictive factor for the negative evolution of HNSCC patients in cases where the cause of clinical failure is tissue invasion (4).

Although the role of MIIs in HNSCC progression is still not clear, the present work suggests that MIIB expression in AE may indicate the potential for regional metastasis and that MIIC expression in the tumoral ZI is predictive of negative evolution of the disease.

\section{References}

1. Bezerra NV, Leite KL, de Medeiros MM, Martins ML, Cardoso AM, Alves PM, et al. Impact of the anatomical location, alcoholism and smoking on the prevalence of advanced oral cancer in Brazil. Medicina oral, patologia oral y cirugia bucal. 2018;23:e295-e301.

2. Jemal A, Bray F, Center MM, Ferlay J, Ward E, Forman D. Global cancer statistics. CA: a cancer journal for clinicians. 2011;61:69-90. 3. Yanamoto S, Kawasaki G, Yamada S, Yoshitomi I, Kawano T, Yonezawa $\mathrm{H}$, et al. Isolation and characterization of cancer stemlike side population cells in human oral cancer cells. Oral oncology. 2011;47:855-60.

4. Painter KJ, Armstrong NJ, Sherratt JA. The impact of adhesion on cellular invasion processes in cancer and development. Journal of theoretical biology. 2010;264:1057-67.

5. Vicente-Manzanares M, Ma X, Adelstein RS, Horwitz AR. Nonmuscle myosin II takes centre stage in cell adhesion and migration. Nature reviews Molecular cell biology. 2009;10:778-90.

6. Hildebrand LC, Carvalho AL, Lauxen IS, Nor JE, Cerski CT, Sant'Ana Filho M. Spatial distribution of cancer stem cells in head and neck squamous cell carcinomas. Journal of oral pathology \& medicine: official publication of the International Association of Oral Pathologists and the American Academy of Oral Pathology. 2014;43:499-506

7. Flores APC, Dias KB, Hildebrand LC, Oliveira MG, Lamers ML, Sant'Ana Filho M. Focal adhesion kinases in head and neck squamous cell carcinoma. Journal of oral pathology \& medicine : official publication of the International Association of Oral Pathologists and the American Academy of Oral Pathology. 2018;47:246-52.

8. Bryne M, Koppang HS, Lilleng R, Kjaerheim A. Malignancy grading of the deep invasive margins of oral squamous cell carcinomas has high prognostic value. The Journal of pathology. 1992;166:37581.

9. Edge SB, Compton CC. The American Joint Committee on Cancer: the 7th edition of the AJCC cancer staging manual and the future of TNM. Annals of surgical oncology. 2010;17:1471-4.

10. Chang JH, Wu CC, Yuan KS, Wu ATH, Wu SY. Locoregionally recurrent head and neck squamous cell carcinoma: incidence, survival, prognostic factors, and treatment outcomes. Oncotarget. 2017;8:55600-12

11. Brown LM, Check DP, Devesa SS. Oral cavity and pharynx cancer incidence trends by subsite in the United States: changing gender patterns. Journal of oncology. 2012;2012:649498.

12. Taghavi N, Yazdi I. Prognostic factors of survival rate in oral squamous cell carcinoma: clinical, histologic, genetic and molecular concepts. Archives of Iranian medicine. 2015;18:314-9.

13. El-Mofty SK. Histopathologic risk factors in oral and oropharyngeal squamous cell carcinoma variants: an update with special reference to HPV-related carcinomas. Medicina oral, patologia oral y cirugia bucal. 2014;19:e377-85.

14. Huang SH, O'Sullivan B. Overview of the 8th Edition TNM Classification for Head and Neck Cancer. Current treatment options in oncology. 2017;18:40.

15. Sterz CM, Kulle C, Dakic B, Makarova G, Bottcher MC, Bette M, et al. A basal-cell-like compartment in head and neck squamous cell carcinomas represents the invasive front of the tumor and is expressing MMP-9. Oral oncology. 2010;46:116-22.

16. Jacobs K, Van Gele M, Forsyth R, Brochez L, Vanhoecke B, De
Wever O, et al. P-cadherin counteracts myosin II-B function: implications in melanoma progression. Molecular cancer. 2010;9:255. 17. Ouderkirk JL, Krendel M. Non-muscle myosins in tumor progression, cancer cell invasion, and metastasis. Cytoskeleton. 2014;71:447-63.

18. Sturgis EM, Cinciripini PM. Trends in head and neck cancer incidence in relation to smoking prevalence: an emerging epidemic of human papillomavirus-associated cancers? Cancer. 2007;110:142935 .

19. Kim L, King T, Agulnik M. Head and neck cancer: changing epidemiology and public health implications. Oncology (Williston Park). 2010;24:915-9, 24.

20. Carrard VC, Filho MS, Rados PV, Chaves AC, Lauxen Ida S. Quantification of silver-staining nucleolar organizer region in epithelial cells of tongue of mice after exposure to, or intake of, alcohol. Alcohol. 2004;34:233-8.

21. Helfman DM, Pawlak G. Myosin light chain kinase and actomyosin contractility modulate activation of the ERK cascade downstream of oncogenic Ras. Journal of cellular biochemistry. 2005;95:1069-80.

22. Yam JW, Chan KW, Hsiao WL. Suppression of the tumorigenicity of mutant $\mathrm{p} 53$-transformed rat embryo fibroblasts through expression of a newly cloned rat nonmuscle myosin heavy chain-B. Oncogene. 2001;20:58-68.

23. Turati F, Garavello W, Tramacere I, Pelucchi C, Galeone C, Bagnardi $\mathrm{V}$, et al. A meta-analysis of alcohol drinking and oral and pharyngeal cancers: results from subgroup analyses. Alcohol and alcoholism. 2013;48(1):107-18.

24. Brabletz T, Jung A, Spaderna S, Hlubek F, Kirchner T. Opinion: migrating cancer stem cells - an integrated concept of malignant tumour progression. Nature reviews Cancer. 2005;5:744-9.

25. Vicente-Manzanares M, Newell-Litwa K, Bachir AI, Whitmore LA, Horwitz AR. Myosin IIA/IIB restrict adhesive and protrusive signaling to generate front-back polarity in migrating cells. The Journal of cell biology. 2011;193:381-96.

26. Maeda J, Hirano T, Ogiwara A, Akimoto S, Kawakami T, Fukui $\mathrm{Y}$, et al. Proteomic analysis of stage I primary lung adenocarcinoma aimed at individualisation of postoperative therapy. British journal of cancer. 2008;98:596-603.

27. Liu D, Zhang L, Shen Z, Tan F, Hu Y, Yu J, et al. Clinicopathological significance of NMIIA overexpression in human gastric cancer. International journal of molecular sciences. 2012;13:15291-304. 28. Schramek D, Sendoel A, Segal JP, Beronja S, Heller E, Oristian $\mathrm{D}$, et al. Direct in vivo RNAi screen unveils myosin IIa as a tumor suppressor of squamous cell carcinomas. Science. 2014;343:309-13. 29. Conti MA, Saleh AD, Brinster LR, Cheng H, Chen Z, Cornelius $\mathrm{S}$, et al. Conditional deletion of nonmuscle myosin II-A in mouse tongue epithelium results in squamous cell carcinoma. Scientific reports. 2015;5:14068.

30. Daniels MJ, Wang Y, Lee M, Venkitaraman AR. Abnormal cytokinesis in cells deficient in the breast cancer susceptibility protein BRCA2. Science. 2004;306:876-9.

31. Jana SS, Kawamoto S, Adelstein RS. A specific isoform of nonmuscle myosin II-C is required for cytokinesis in a tumor cell line. The Journal of biological chemistry. 2006;281:24662-70.

32. Takaoka M, Saito H, Takenaka K, Miki Y, Nakanishi A. BRCA2 phosphorylated by PLK1 moves to the midbody to regulate cytokinesis mediated by nonmuscle myosin IIC. Cancer research. 2014;74:1518-28.

\section{Conflict of Interest}

The authors have declared that no conflict of interest exist. 